\title{
Fibronectin Degradation Products Containing the Cytoadhesive Tetrapeptide Stimulate Human Neutrophil Degranulation
}

Yanina T. Wachtfogel, William Abrams, Umberto Kucich, George Weinbaum, Marc Schapira, and Robert W. Colman Thrombosis Research Center and the Hematology-Oncology Section, Department of Medicine, Temple University School of Medicine, Philadelphia, Pennsylvania 19140; Graduate Hospital Research Division, Department of Medicine, Philadelphia, Pennsylvania 19146; and Hemostasis and Thrombosis Laboratory, Vanderbilt University Medical Center, Nashville, Tennessee 37232

\begin{abstract}
We investigated whether adhesive glycoproteins, such as fibronectin or fibrinogen, could function to provide a nidus for neutrophil degranulation. Elastase release in recalcified plasma was normal in afibrinogenemic plasma, but $73 \%$ less in plasma depleted of fibronectin. Proteolytic digests of fibronectin, but not intact fibronectin $(50-1,000 \mu \mathrm{g} / \mathrm{ml})$, induced a concentration-dependent release of neutrophil elastase and lactoferrin. MAbs N293, which recognized the mid-molecule of fibronectin, N294, which was directed toward the 11-kD cell adhesive fragment, and N295, generated against the amino terminal of the 11-kD fragment, inhibited the release of elastase by 7,24 , and $60 \%$, respectively. The cytoadhesive tetrapeptide portion of fibronectin, Arg-Gly-Asp-Ser $(250-1,000 \mu \mathrm{g} / \mathrm{ml})$, released $1.94 \pm 0.10 \mu \mathrm{g} / \mathrm{ml}$ of elastase from $10^{7}$ neutrophils, in contrast to the lack of release by the control hexapeptide, Arg-GlyTyr-Ser-Leu-Gly. Plasmin appeared to be the enzyme responsible for fibronectin cleavage, since neutrophil elastase release in plasma that had been depleted of plasminogen was decreased and reconstitution of plasminogen-deficient plasma with purified plasminogen corrected the abnormal release. Plasmin cleaved fibronectin to multiple degradation products, each $<200 \mathrm{kD}$. This fibronectin digest released $1.05 \mu \mathrm{g} / \mathrm{ml}$ of elastase from $10^{7}$ neutrophils. We suggest that the activation of plasminogen leads to the formation of fibronectin degradation products capable of functioning as agonists for neutrophils.
\end{abstract}

\section{Introduction}

Upon activation, human neutrophils exhibit increased oxygen consumption (1), phagocytosis (2), chemotaxis (3), degranulation (4), aggregation (5), and calcium mobilization (6). Three plasma polypeptides, C5a $(5,7)$, kallikrein $(8-11)$, and Factor

Address reprint requests to Dr. Robert W. Colman, Thrombosis Research Center, Temple University, 3400 N. Broad Street, Philadelphia, PA 19140.

This work was presented in part at the American Society of Hematology Meeting, New Orleans, LA, 7-10 December 1985, and published in abstract form in 1985 (Blood. 66:345a). It was also presented in part at the American Federation for Clinical Research Meeting, Washington, DC, 2-5 May 1986, and published in abstract form in 1986 (Clin. Res. 34:427a).

Received for publication 26 August 1987 and in revised form 30 October 1987.

J. Clin. Invest.

(C) The American Society for Clinical Investigation, Inc. 0021-9738/88/05/1310/07 \$2.00

Volume 81, May 1988, 1310-1316
XIIa (12), which stimulate neutrophils, have been described. Other neutrophil agonists that can produce these responses include the bacterial chemotactic peptide, $N$-formyl-Met-LeuPhe $(13,14)$, and the nonphysiological stimulator of protein kinase C, phorbol myristate acetate (15). Plow (16) has shown that human neutrophils release elastase during blood coagulation independently of thrombin. Human neutrophils, resuspended in plasma deficient in either the plasma complement protein, C5, or the plasma contact zymogen, Factor XI, release elastase in amounts similar to neutrophils exposed to normal plasma (11), signifying that neither C5 nor Factor XI in normal human plasma is responsible for the degranulation. However, neutrophils resuspended in either prekallikrein or Factor XII-deficient plasma release only $25-30 \%$ of the elastase released by exposure to normal human plasma (11). To try to explain this residual $25-30 \%$ of elastase released by normal human plasma, we sought to investigate whether plasma-adhesive glycoproteins, such as fibrinogen, which is known to be necessary for platelet aggregation (17), or fibronectin, which is recognized as an opsonin that enhances phagocytosis by neutrophils (18), could serve as possible neutrophil agonists.

\section{Methods}

\section{Materials}

Gelatin-Sepharose, lysine-Sepharose, aprotinin, and methoxy-succinyl-Ala-Ala-Pro-Val-p-nitroanilide were purchased from Sigma Chemical Co., St. Louis, MO. A system to measure functional plasminogen concentrations, Coatest Plasminogen Kit, and human plasmin were generous gifts of KabiVitrum, Stockholm, Sweden. Reagents to assay lactic dehydrogenase, Statzyme LDH (L-P), were purchased from Worthington Diagnostics Division, Freehold, NJ. HBSS was purchased from Gibco Laboratories, Grand Island, NY. Flat-bottomed 96-well polystyrene microtiter plates (Immulon No. 2) were obtained from Dynatech Laboratories Inc., Alexandria, VA. MAbs directed against the mid-molecule (N293), cell-binding site (N294), and cellbinding peptide (N295) of fibronectin were purchased from Peninsula Laboratories, Inc., Belmont, CA. Iodogen (chloramide, 1,3,4,6-tetrachloro-3 alpha, 6 alpha-diphenylglycoluril) was obtained from Pierce Chemical Co., Rockford, IL. ${ }^{125} \mathrm{I}-\mathrm{Na}(50 \mathrm{mCi} / \mathrm{mmol})$ was obtained from ICN Pharmaceuticals, Irvine, CA.

\section{Procedures}

Plasma. With informed consent, venous blood from normal volunteers was collected directly into polypropylene tubes containing 1 vol trisodium citrate (final concentration $11 \mathrm{mM}$ ) for each 9 vol of whole blood. Anticoagulated blood was centrifuged at $500 \mathrm{~g}$ for $15 \mathrm{~min}$ to remove most cells, and the supernatant plasma at $27,000 \mathrm{~g}$ for $15 \mathrm{~min}$ to prepare cell-free normal human plasma. Afibrinogenemic plasma ( $<150 \mu \mathrm{g} / \mathrm{ml}$ ) was purchased from George King Biomedicals, Overland Park, KS. Normal plasma was depleted of fibronectin via gelatinSepharose column chromatography (19). The fibronectin-depleted plasma used in our experiments was determined to contain $<0.2$ $\mu \mathrm{g} / \mathrm{ml}$ fibronectin using an ELISA for fibronectin (20). Plasma was 
depleted of plasminogen via lysine-Sepharose column chromatography (21). The plasminogen-depleted plasma used in our experiments was determined to contain $<0.5 \mu \mathrm{g} / \mathrm{ml}$ plasminogen, after activation to plasmin with streptokinase, using a chromogenic substrate S-2251 (22)

Purified blood proteins. Fibronectin was purchased from Pierce Chemical Co. On 3.2-15\% gradient SDS-PAGE (23), in the presence of reducing agent, the intact fibronectin appeared as a doublet of $M_{\mathrm{r}}$ $=200,000$ and 250,000 (Fig. 1). The fibronectin remained intact when lyophilized and stored at $-70^{\circ} \mathrm{C}$. However, there was a disappearance of the dimer and appearance of multiple components below $M_{\mathrm{r}}$ $=200,000$ in fibronectin solutions that had been stored at $4^{\circ} \mathrm{C}$ without the addition of exogenous inhibitors of proteolysis (Fig. 1). This preparation is referred to as fibronectin degradation products (FNDPs). ${ }^{1}$ Intact fibronectin was radiolabeled with ${ }^{125} \mathrm{I}-\mathrm{Na}$ using lodogen by the method of Freker and Speck (24).

Neutrophil isolation. Approximately $8 \times 10^{8}$ neutrophils of $>98 \%$ purity and viability were isolated as previously described $(11,12)$.

Neutrophil degranulation in an in vitro plasma system. $1 \times 10^{7} / \mathrm{ml}$ neutrophils were resuspended in polypropylene tubes containing normal plasma, deficient plasma, or deficient plasma that had been reconstituted with its deficient plasma protein. Calcium (final concentration $30 \mathrm{mM}$ ) was added, but due to the presence of citrate and the calcium binding properties of albumin, the free calcium concentration was $\sim 5 \mathrm{mM}$. Incubations were performed for various times at $23^{\circ} \mathrm{C}$, and aliquots were then removed and centrifuged at $13,000 \mathrm{~g}$ for $5 \mathrm{~min}$ at $23^{\circ} \mathrm{C}$ in a microcentrifuge (model 235A; Fisher Scientific Co., Pittsburgh, PA). The plasma supernatants were stored at $-70^{\circ} \mathrm{C}$ until immunochemical determinations of elastase were made, using an indirect competitive ELISA $(11,12)$.

Neutrophil degranulation in an in vitro plasma-free system. 1 $\times 10^{7} / \mathrm{ml}$ neutrophils were incubated in polypropylene tubes at $37^{\circ} \mathrm{C}$ in HBSS in the presence of varying concentrations of agonist. After a 20-min incubation, mixtures were centrifuged and stored until lactoferrin was measured, using an indirect competitive ELISA (12), and elastase was measured, using the chromogenic substrate methoxy-succinyl-Ala-Ala-Pro-Val-p-nitroanalide (25).

Lactate dehydrogenase assay. Release of the cytoplasmic enzyme, lactate dehydrogenase, was monitored on aliquots of supernatants after cell incubations and on $0.1 \%$ Triton X-100 extracts of neutrophils by the method of Wacker et al. (26), to determine whether neutrophil lysis had occurred during incubations with the agonists.

Proteolytic digestion of fibronectin by plasmin. $58 \mu \mathrm{g}$ intact fibronectin was incubated at a 10:1 molar ratio (substrate/enzyme) with 1 $\mu \mathrm{g}$ plasmin. At various times aliquots were removed and degradation was terminated with the addition of aprotinin (10-fold molar excess). On 3.2-15\% gradient SDS-PAGE (23), in the presence of reducing agent, the intact fibronectin appeared as a doublet of $M_{\mathrm{r}}=200,000$ and 250,000 (Fig. 2). Within the first 15 min of plasmin treatment, multiple components of $M_{\mathrm{r}}=100,000-200,000$ appeared. By $150 \mathrm{~min}$ there was further degradation, and by $300 \mathrm{~min}$ the fibronectin appeared to have been cleaved to fragments of $M_{\mathrm{r}}<100,000$.

\section{Results}

Release of elastase in plasma. $1 \times 10^{7}$ neutrophils, resuspended in $1 \mathrm{ml}$ of normal human plasma in polypropylene tubes at $23^{\circ} \mathrm{C}$ in the presence of $30 \mathrm{mM} \mathrm{CaCl}_{2}$ for $60 \mathrm{~min}$, released $2.35 \mu \mathrm{g} / \mathrm{ml}$ of elastase. When plasma containing $<150 \mu \mathrm{g} / \mathrm{ml}$ of fibrinogen was used under the same conditions, $2.12 \mu \mathrm{g} / \mathrm{ml}$ of elastase was released, equivalent to $90 \%$ of that released in normal plasma. In contrast, when fibronectindepleted plasma was employed, $0.63 \mu \mathrm{g} / \mathrm{ml}$ of elastase was

1. Abbreviations used in this paper: FNDP, fibronectin degradation product.

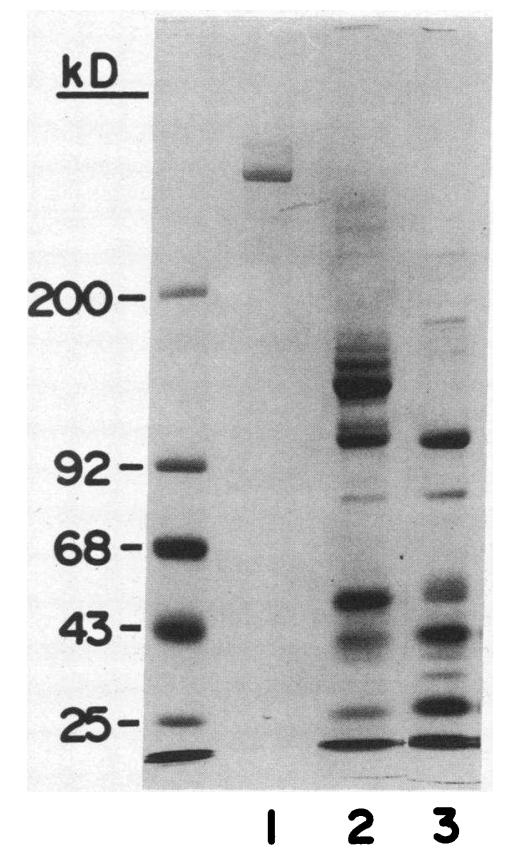

Figure 1. Affinity-purified fibronectin. SDS-polyacrylamide gradient (3.2-15\%) gel electrophoretic pattern of intact fibronectin (lane 1) and FNDPs obtained from two separate preparations of fibronectin stored in the absence of any added inhibitors of proteolysis (lanes 2 and 3 ).

\section{TIME (min)

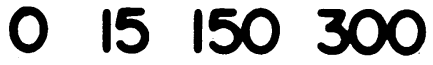

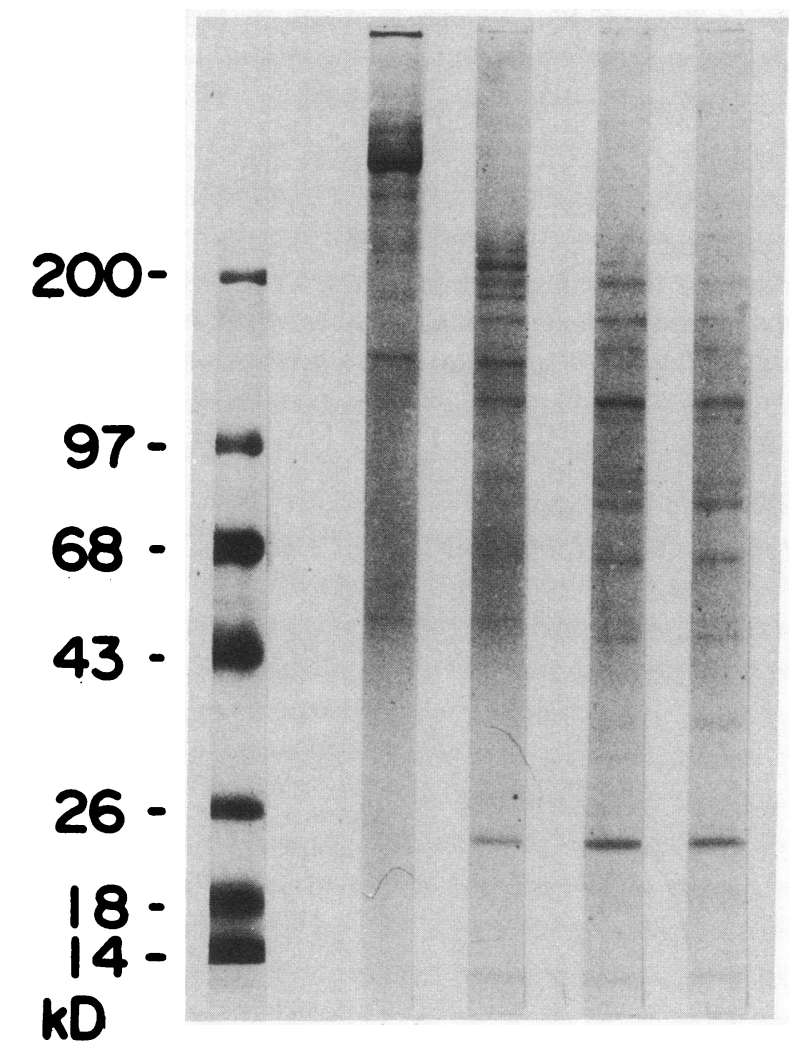

Figure 2. Proteolytic cleavage of fibronectin by plasmin. SDS-polyacrylamide gradient (3.2-15\%) gel electrophoretic pattern of intact fibronectin and $58 \mu \mathrm{g}$ fibronectin incubated with $1 \mu \mathrm{g}$ plasmin at a 10:1 molar ratio at $37^{\circ} \mathrm{C}$ for 15,150 , and $300 \mathrm{~min}$. 
Table I. Effect of Adhesive Glycoproteins in Plasma on Neutrophils

\begin{tabular}{lcc}
\hline & Elastase released & $\begin{array}{c}\text { Elastase released } \\
\text { by normal } \\
\text { human plasma }\end{array}$ \\
\hline & $\mu \mathrm{g} / \mathrm{ml}$ & $\%$ \\
$\begin{array}{l}\text { Normal human plasma } \\
\text { Afibrinogenemic plasma } \\
(<150 \mu \mathrm{g} / \mathrm{ml})\end{array}$ & 2.35 & 100 \\
$\begin{array}{l}\text { Fibronectin-depleted plasma } \\
(<0.2 \mu \mathrm{g} / \mathrm{ml})\end{array}$ & 2.12 & 90 \\
\hline
\end{tabular}

$1 \times 10^{7} / \mathrm{ml}$ neutrophils were resuspended in normal, afibrinogenemic, or fibronectin-depleted human plasma, all of which contained $30 \mathrm{mM} \mathrm{CaCl}_{2}$. Incubations were performed in polypropylene tubes at $23^{\circ} \mathrm{C}$ for $60 \mathrm{~min}$, followed by centrifugation at $13,000 \mathrm{~g}$ for $5 \mathrm{~min}$. Supernatants were assayed for immunochemical levels of elastase.

released, equivalent to $27 \%$ of that released in normal plasma (Table I). Elastase was released in a time-dependent manner from neutrophils resuspended in normal human plasma (Fig. 3). With fibronectin-depleted plasma, however, elastase was released at a slower rate, and only $27 \%$ as much elastase was released as when normal plasma was present at $60 \mathrm{~min}$ (Fig. 3).

Neutrophil degranulation by fibronectin degradation products. Incubation of $100-1,000 \mu \mathrm{g} / \mathrm{ml}$ intact fibronectin with $10^{7}$ neutrophils in $1 \mathrm{ml}$ HBSS in polypropylene tubes for 20 min at $37^{\circ} \mathrm{C}$ resulted in little elastase release (Fig. 4). However, when $50-1,000 \mu \mathrm{g} / \mathrm{ml} \mathrm{FNDPs} \mathrm{were} \mathrm{incubated} \mathrm{with} 10^{7}$ neutrophils under the same conditions, a concentration-dependent release of elastase occurred, reaching a maximum of $5.45 \pm 0.58 \mu \mathrm{g} / \mathrm{ml}$ of elastase released with $\sim 800 \mu \mathrm{g} / \mathrm{ml}$ of FNDPs (Fig. 4). Concomitantly, we found that $2.77 \mu \mathrm{g} / \mathrm{ml}$ of lactoferrin was released with $\sim 800 \mu \mathrm{g} / \mathrm{ml}$ of FNDPs. This release was not due to cell lysis, since $<2 \%$ of the lactate dehydrogenase that can be solubilized by $0.1 \%$ Triton X-100 appeared in the supernatants of all samples exposed to FNDPs.

Identification of the domain of fibronectin responsible for neutrophil activation by MAbs. $0.7 \mu \mathrm{M}$ FNDPs were preincubated for $5 \mathrm{~min}$ at $37^{\circ} \mathrm{C}$ with $2.5 \mu \mathrm{M} \mathrm{MAb}, \mathrm{N} 293$, which is directed against the mid-molecule of fibronectin. The mixture was then incubated with $10^{7}$ neutrophils in $1 \mathrm{ml}$ HBSS in polypropylene tubes for $20 \mathrm{~min}$ at $37^{\circ} \mathrm{C}$. The results are pre-

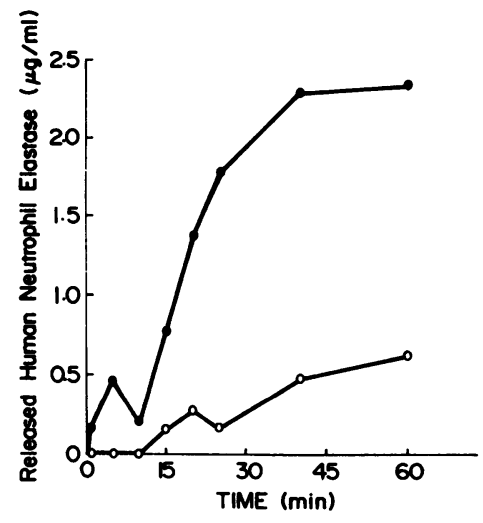

Figure 3. Influence of fibronectin on release of elastase from neutrophils in plasma. $1 \times 10^{7} / \mathrm{ml}$ neutrophils were resuspended in normal (•) or fibronectindepleted (o) human plasma containing $30 \mathrm{mM} \mathrm{CaCl}_{2}$ in polypropylene tubes at $23^{\circ} \mathrm{C}$. At indicated times, aliquots were centrifuged at $13,000 \mathrm{~g}$ for $5 \mathrm{~min}$ and immunochemical levels of elastase were determined. This is a representative figure of three separate experiments.

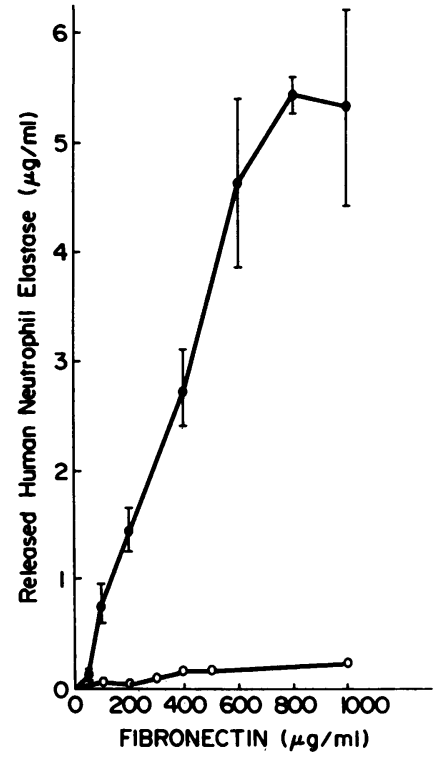

sented in Table II. We observed a release of $2.07 \mu \mathrm{g} / \mathrm{ml}$ of elastase, accounting for a 7\% inhibition of the $2.23 \mu \mathrm{g} / \mathrm{ml}$ of elastase released by FNDPs alone. Similar testing of N294, an $\mathrm{MAb}$ directed against the cell-binding portion of fibronectin, resulted in a $24 \%$ inhibition of degranulation. The MAb directed against the cell-binding peptide of fibronectin, N295, inhibited $60 \%$ of the degranulation induced by FNDPs alone.

Release of elastase by the tetrapeptide, Arg-Gly-Asp-Ser. When $10^{7}$ neutrophils were resuspended in $1 \mathrm{ml}$ HBSS in polypropylene tubes for $20 \mathrm{~min}$ at $37^{\circ} \mathrm{C}$ with $250-1,000 \mu \mathrm{g} / \mathrm{ml}$ of Arg-Gly-Asp-Ser, a concentration-dependent release of elastase was observed, reaching a maximum of $1.95 \pm 0.25$ $\mu \mathrm{g} / \mathrm{ml}$ of extracellular elastase between 750 and $1,000 \mu \mathrm{g} / \mathrm{ml}$ of the tetrapeptide (Fig. 5). When aspartic acid was replaced with tyrosine at the third position, we observed little elastase release, as shown by using the hexapeptide Arg-Gly-Tyr-SerLeu-Gly over the same concentration range (Fig. 5).

Table II. MAbs Inhibit FNDP'' Effect on Elastase Release from Neutrophils

\begin{tabular}{lcc}
\hline & Elastase released & $\begin{array}{c}\text { Inhibition } \\
\text { by MAb }\end{array}$ \\
& $\mu g / m l$ & $\%$ \\
FNDPs Alone & 2.23 & 0 \\
FNDPs + MAb & (mid- \\
$\quad$ molecule) N293 & 2.07 & 7 \\
FNDPs + MAb & & \\
site) N294 & 1.70 & 24 \\
FNDPs + MAb (cell-binding & & \\
peptide) N295 & 0.89 & 60 \\
\end{tabular}

$0.7 \mu \mathrm{M}$ FNDPs alone or $0.7 \mu \mathrm{M}$ FNDPs preincubated with either 2.5 $\mu \mathrm{M}$ MAb directed against either the mid-molecule, the cell-binding site, or the cell-binding peptide of fibronectin were incubated for 20 min at $37^{\circ} \mathrm{C}$ with $1 \times 10^{7} / \mathrm{ml}$ neutrophils in HBSS. Samples were centrifuged at $13,000 \mathrm{~g}$ for $5 \mathrm{~min}$ at $23^{\circ} \mathrm{C}$ and elastase activity was measured in these supernatants. The value for elastase release was corrected by subtracting the amount released in the presence of each MAb alone. 


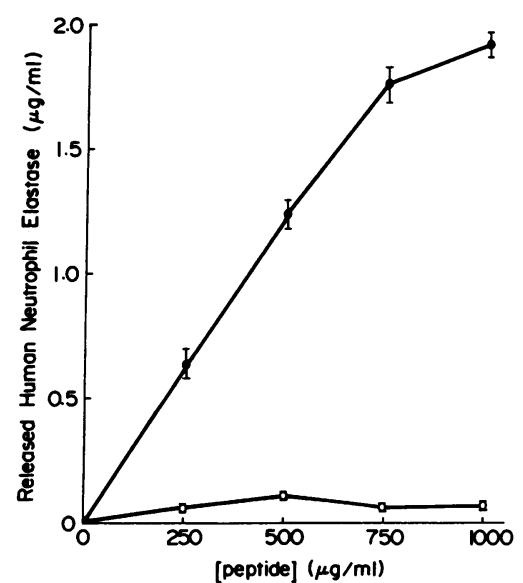

Release of elastase by fibronectin digested with plasmin $600 \mu \mathrm{g} / \mathrm{ml}$ intact fibronectin (Fig. 2) released only $0.1 \mu \mathrm{g} / \mathrm{ml}$ of elastase from neutrophils (Fig. 6). However, $58 \mu \mathrm{g}$ fibronectin that had been degraded by $1 \mu \mathrm{g}$ plasmin for $15-150 \mathrm{~min}$ at $37^{\circ} \mathrm{C}$ (Fig. 2) released $1.05-1.20 \mu \mathrm{g} / \mathrm{ml}$ of elastase from neutrophils. Extensive degradation of fibronectin by plasmin for 300 min (Fig. 2) induced $1.60 \mu \mathrm{g} / \mathrm{ml}$ of elastase release (Fig. 6).

Release of elastase in plasminogen-depleted plasma. 1 $\times 10^{7}$ neutrophils, resuspended in $1 \mathrm{ml}$ normal human plasma in polypropylene tubes at $23^{\circ} \mathrm{C}$ in the presence of $30 \mathrm{mM}$ $\mathrm{CaCl}_{2}$ for $30 \mathrm{~min}$, exhibited a time-dependent release of elastase, reaching a maximum of $3.00 \mu \mathrm{g}$ of elastase per milliliter of plasma in this set of experiments. Plasma deficient in plasminogen induced a release of decreased elastase from neutrophils, with a maximum of $1.11 \mu \mathrm{g} / \mathrm{ml}$ of elastase released at 30 min. Reconstitution of plasminogen-deficient plasma with purified plasminogen restored both the rate and magnitude of the release of elastase (Fig. 7). To directly demonstrate that plasmin could degrade fibronectin in the plasma milieu, we added

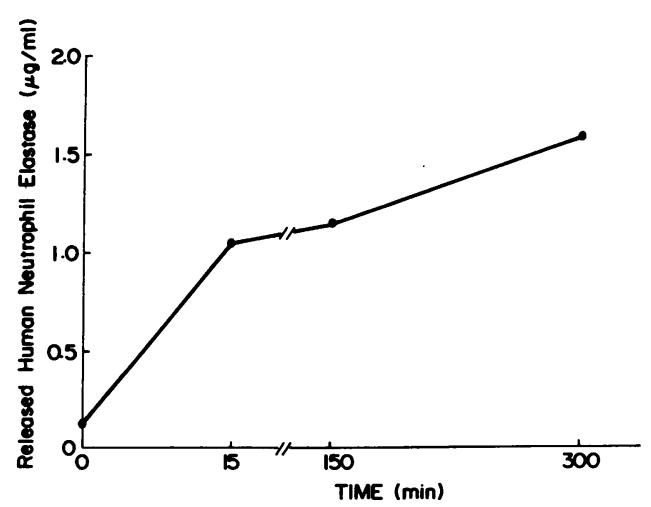

Figure 6. Elastase released by plasmin-digested fibronectin. 600 $\mu \mathrm{g} / \mathrm{ml}$ fibronectin that was digested by plasmin for various time periods was incubated for $20 \mathrm{~min}$ at $37^{\circ} \mathrm{C}$ with $1 \times 10^{7} / \mathrm{ml}$ neutrophils in HBSS. Samples were centrifuged at $13,000 \mathrm{~g}$ for $5 \mathrm{~min}$ at $23^{\circ} \mathrm{C}$ and elastase activity was measured in these supernatants. This is a representative figure of three separate experiments. Zero time values are the same as for intact fibronectin.

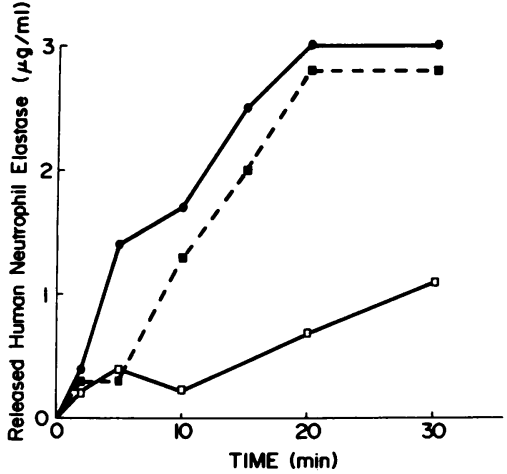

Figure 7. Influence of plasmin on release of elastase from neutrophils in plasma. 1 $\times 10^{7} / \mathrm{ml}$ neutrophils were resuspended in normal $(\bullet)$, plasminogen-depleted ( $\square$ ), and plasminogen-depletedreconstituted-with-plasminogen ( $($ ) human plasma containing 30 $\mathrm{mM} \mathrm{CaCl} 2$ in polypropylene tubes at $23^{\circ} \mathrm{C}$.

At various times aliquots were centrifuged at $13,000 \mathrm{~g}$ for $5 \mathrm{~min}$ and immunochemical levels of elastase were determined. This is a representative figure of three separate experiments.

$10 \mu \mathrm{g}{ }^{125} \mathrm{I}$-fibronectin to $20 \mu \mathrm{l}$ of normal plasma and incubated the mixture with $0.03-3.0 \mu \mathrm{g}$ plasmin. In addition, radiolabeled fibronectin was degraded with plasmin, in the absence of plasma, under the same conditions. The reactions were terminated by boiling in electrophoresis buffer (23). Autoradiography revealed that the radiolabeled fibronectin in normal plasma appeared as a doublet of $M_{\mathrm{r}}=200,000$ and 250,000 . Plasmin, at all concentrations tested, completely degraded the ${ }^{125}$ I-fibronectin in plasma to a single species of $\sim M_{\mathrm{r}}=40,000$. Plasmin, in the absence of plasma, completely degraded the ${ }^{125}$ I-fibronectin to peptides that were not resolved from the dye front of the gel.

\section{Discussion}

Activation of neutrophils and the associated elastase release are promoted by plasma proteins in the presence of calcium (16). Although prekallikrein (11) and Factor XII (12) are important, they do not account for all of the degranulation noted, since, in the absence of either, about one-third of the maximum elastase release occurs. This study identifies fibronectin as another contributor to the release of elastase by neutrophils. Evidence for this conclusion is that neutrophils resuspended in fibronectin-depleted plasma released only $27 \%$ of the elastase as compared with that occurring during exposure to normal plasma (Table I, Fig. 3). Although intact fibronectin did not stimulate neutrophil degranulation, a proteolytic digest of the fibronectin molecule was stimulatory (Fig. 4).

The requirement for cleavage of the fibronectin molecule is observed in the study of human peripheral blood monocytes, which are stimulated to a chemotactic response by proteolytic fragments of fibronectin (27), but not by the intact molecule. Additionally, these hydrolysis products are capable of enhancing macrophage phagocytosis of gelatinized particles (28), as well as mediating fibrin monomer binding to peripheral macrophages (29). Fibronectin is clearly fragmented by proteolytic enzymes. We demonstrated in this study that plasmin digestion of fibronectin generated degradation products that were capable of activating neutrophils (Fig. 6), comparable to the studies of Rourke et al. (28) and Horman et al. (29) with macrophages.

We observed that neutrophils, resuspended in plasma depleted of plasminogen, released only $37 \%$ of the elastase as compared with normal plasma. Furthermore, reconstitution 
of plasminogen-depleted plasma with purified plasminogen restored the ability of the plasma to release elastase from neutrophils (Fig. 7), attesting to the specificity of the observation. Furthermore, plasmin, added to plasma, is capable of degrading fibronectin to an FNDP of $\sim M_{\mathrm{r}}=40,000$.

Plasminogen activator is located in the specific granules of the neutrophil and is translocated to the cell surface by exocytosis (30). The concentration of plasmin necessary for FNDP production $(1.5 \mu \mathrm{g} / \mathrm{ml})$ represented a $<2 \%$ activation of plasma plasminogen. Therefore, plasmin generated in plasma containing neutrophils may be responsible for producing the FNDPs necessary to stimulate elastase release. Thus, agonists such as kallikrein (11) or Factor XIIa (12), which form during recalcification of plasma, could cause exocytosis of plasminogen activators. The release of these activators would allow plasmin formation and subsequent production of FNDPs, which would further augment the neutrophil response.

Alpha $_{2}$ plasmin-inhibitor rapidly inhibits plasmin in purified systems (31). However, in the blood, several protective mechanisms may protect plasmin from inhibition. Cell surfaces may prevent alpha $a_{2}$ plasmin-inhibitor from forming a complex with plasmin (32). In plasma, alpha ${ }_{2}$ macroglobulin, while partially inhibiting plasmin, allows expression of a fraction of its proteolytic activity and protects it from further inhibition (33). Finally, the binding of plasmin to substrates such as fibronectin or fibrinogen may modulate inhibition.

Plasmin also cleaves fibrinogen (34) which, like fibronectin, contains the cytoadhesive tetrapeptide, Arg-Gly-Asp-Ser (35). Neutrophils resuspended in afibrinogenemic plasma released levels of elastase similar to that of normal plasma. Elastase release was $73 \%$ less in plasma depleted only of fibronectin (Table I, Fig. 3). Therefore, it is likely that plasmin digestion of fibrinogen does not unmask the same neutrophil recognition site.

The domain of fibronectin that appears to be responsible for elastase release resides in its $11-\mathrm{kD}$ cell-adhesive portion, since MAbs directed against that region of the molecule inhibit the release of elastase by FNDPs (Table II). Moreover, the cytoadhesive tetrapeptide, Arg-Gly-Asp-Ser, located in the 11-kD cell-adhesive region of fibronectin (36), was found to stimulate neutrophil degranulation (Fig. 5). However, the replacement of the aspartic acid at the third position with a tyrosine yielded no detectable elastase release, even with the relatively high concentrations of this hexapeptide, Arg-GlyTyr-Ser-Leu-Gly. This observation is not surprising, since only the unmodified cytoadhesive tetrapeptide has been demonstrated to support adherence of fibronectin to fibroblasts (36).

Ginsberg and co-workers (37) have found that this cytoadhesive tetrapeptide inhibits binding of fibronectin to platelets, suggesting that it defines a discrete minimal recognition specificity of fibronectin for platelets and other cells. They suggested that since intact fibronectin has a greater affinity for the platelet than the cytoadhesive tetrapeptide, there should be secondary binding sites in the fibronectin molecule that also interact with the platelet, as has been suggested for fibrinogen (38) and vWf (39). Similar considerations apply to the neutrophil, since FNDPs stimulate neutrophils at much lower concentrations than the cytoadhesive tetrapeptide. Fibronectin has also been shown to mediate the attachment of Staphylococcus aureus to neutrophils, even though it was not able to promote neutrophil phagocytosis of bacteria (40).

The cytoadhesive tetrapeptide also inhibits thrombin-in- duced platelet aggregation and fibrinogen binding (37, 41). Additionally, a synthetic peptide containing Arg-Gly-Asp-Ser has been shown to inhibit experimental metastasis of murine melanoma cells (42). This tetrapeptide sequence is present in at least three other proteins, and may allow similar interactions for these ligands with an attachment site on the neutrophil. Thus, platelet glycoprotein $\mathrm{II}_{b}-\mathrm{III}_{\mathrm{a}}$ complexes bind fibronectin, fibrinogen, and vWf, implicating Arg-Gly-Asp-Ser as partly responsible for the binding $(43,44)$.

The pathophysiologic consequences of the new effects of fibronectin in neutrophil function described above are incompletely understood. Recently, a familial decrease of fibronectin was reported with a proband that had $30 \%$ of the normal fibronectin concentrations exhibiting defective neutrophil phagocytosis (45). Patients suffering from severe disseminated intravascular coagulation (46), proteinuria (47), starvation (48), liver disease (49), and Schulman's syndrome (50), as well as surgical intensive care patients (51) or those undergoing cardiopulmonary bypass (52), exhibit pronounced changes in their circulating plasma fibronectin concentration and structure. In any or all of these clinical situations, alterations in fibronectin would be expected to affect the inflammatory response.

The activation of neutrophils and subsequent release of elastase, one of the major lysosomal enzymes in the azurophilic granules $(53,54)$, may produce many deleterious effects. Elastase has been shown to attack the lung parenchyma (55), produce endothelial injury (56), expose fibrinogen receptors on the platelet surface (57), reduce the number of thrombinbinding sites per platelet (58), alter other coagulation proteinases (59-61), degrade fibronectin (62), and act as a potent fibrinogenolytic and fibrinolytic enzyme (63). This study indicates that the association of fibronectin degradation with elastase release may be another component of the inflammatory response.

\section{Acknowledgments}

The authors thank Dr. Melvin C. Yoder for performing the ELISA for fibronectin.

This work was supported in part by National Institutes of Health grants HL-06626, HL-19055, HL-24365, HL-29702, HL-29734, and HL-36579; a grant from the Ben Franklin Partnership Fund; and a grant from the Southeastern Pennsylvania Chapter of the American Heart Association.

\section{References}

1. Baldridge, C. W., and R. W. Gerard. 1933. The extra respiration of phagocytosis. Am. J. Physiol. 103:235-236.

2. Mudd, S., M. McCutcheon, and B. Lucke. 1934. Phagocytosis. Physiol. Rev. 14:210-275.

3. McCutcheon, M. 1946. Chemotaxis in leukocytes. Physiol. Rev. 26:319-336.

4. Hirsch, J. G., and Z. A. Cohn. 1960. Degranulation of polymorphonuclear leukocytes following phagocytosis of microorganisms. $J$. Exp. Med. 112:1005-1015.

5. Craddock, P. R., D. Hammerschmidt, J. G. White, A. P. Dalmasso, and H. S. Jacob. 1977. Complement (C5a)-induced granulocyte aggregation in vitro. J. Clin. Invest. 60:260-264.

6. Naccache, P. H., H. J. Showell, E. L. Becker, and R. I. Sha'afi. 1977. Transport of sodium, potassium, and calcium across rabbit polymorphonuclear leukocyte membranes. J. Cell Biol. 73:428-444.

7. Goldstein, I. M., and G. Weissmann. 1974. Generation of C5- 
derived lysosomal enzyme-releasing activity (C5a) by lysates of leukocyte lysosomes. J. Immunol. 113:1583-1588.

8. Kaplan, A. P., A. B. Kay, and K. F. Austen. 1972. A prealbumin activator of prekallikrein III. Appearance of chemotactic activity for human neutrophils by the conversion of human prekallikrein to kallikrein. J. Exp. Med. 135:81-97.

9. Goetzl, E. J., and K. F. Austen. 1974. Stimulation of human neutrophil aerobic glucose metabolism by purified chemotactic factors. J. Clin. Invest. 53:591-599.

10. Schapira, M., E. Despland, C. F. Scott, L. A. Boxer, and R. W. Colman. 1982. Purified human plasma kallikrein aggregates human blood neutrophils. J. Clin. Invest. 69:1191-1202.

11. Wachtfogel, Y. T., U. Kucich, H. L. James, C. F. Scott, M. Schapira, M. Zimmerman, A. B. Cohen, and R. W. Colman. 1983. Human plasma kallikrein releases neutrophil elastase during blood coagulation. J. Clin. Invest. 72:1672-1677.

12. Wachtfogel, Y. T., R. A. Pixley, U. Kucich, W. Abrams, G. Weinbaum, M. Schapira, and R. W. Colman. 1986. Purified plasma Factor XIla aggregates human neutrophils and causes degranulation. Blood. 67:1731-1737.

13. O'Flaherty, J. T., and P. A. Ward. 1978. Leukocyte aggregation induced by chemotactic factors. Inflammation. 3:177-194.

14. Becker, E. L. 1976. Some interrelations of neutrophil chemotaxis, lysosomal enzyme secretion, and phagocytosis as revealed by synthetic peptides. Am. J. Pathol. 85:385-394.

15. Fletcher, M. P., and J. I. Gallin. 1980. Degranulating stimuli increase the availability of receptors on human neutrophils for the chemoattractant f-Met-Leu-Phe. J. Immunol. 124:1585-1588.

16. Plow, E. F. 1982. Leukocyte elastase release during blood coagulation. A potential mechanism for activation of the alternative fibrinolytic pathway. J. Clin. Invest. 69:564-572.

17. Marguerie, G. A., E. F. Plow, and T. S. Edgington. 1979. Human platelets possess an inducible and saturable receptor specific for fibrinogen. J. Biol. Chem. 254:5357-5363.

18. Alexander, J. W., M. A. McClellan, C. K. Ogle, and J. D. Ogle. 1976. Consumptive opsoninopathy: possible pathogenesis in lethal and opportunistic infections. Ann. Surg. 184:672-678.

19. Miekka, S. I., K. C. Ingham, and D. Menache. 1982. Rapid methods for isolation of human plasma fibronectin. Thromb. Res. 27:1-14.

20. Yoder, M. C., S. D. Douglas, J. Gerdes, J. Kline, and R. A. Polin. 1983. Plasma fibronectin in healthy newborn infants: respiratory distress syndrome and perinatal asphyxia. J. Pediatr. 102:777780.

21. Deutsch, D. G., and E. T. Mertz. 1970. Plasminogen: purification from human plasma by affinity chromatography. Science (Wash. DC). 170:1095-1096.

22. Friberger, P. 1982. Method for the assay of plasminogen in plasma. Scand. J. Clin. Lab. Invest. 42:49-54.

23. Laemmli, U. K. 1970. Cleavage of structural proteins during the assembly of the head of bacteriophage T4. Nature (Lond.). 227:680-685.

24. Freker, P. J., and S. C. Speck, Jr. 1978. Protein and cell iodinations with a sparingly soluble chloroamide 1,3,4,6-tetrachloro-3 alpha, 6 alpha-diphenylglycoluril. Biochem. Biophys. Res. Commun. 80:849-857.

25. Nakajima, K., J. C. Powers, B. M. Ashe, and M. Zimmerman. 1979. Mapping the extended substrate binding site of cathepsin $G$ and human leukocyte elastase. J. Biol. Chem. 254:4027-4032.

26. Wacker, W. E. C., D. D. Ulmer, and B. L. Vallee. 1956. Metalloenzymes and myocardial infarction. N. Engl. J. Med. 255:449-456.

27. Norris, D. A., R. A. F. Clark, L. M. Swigart, J. C. Huff, W. L. Weston, and S. E. Howell. 1982. Fibronectin fragment(s) are chemotactic for human peripheral blood monocytes. J. Immunol. 129:16121618.

28. Rourke, F. J., F. A. Blumenstock, and J. E. Kaplan. 1984. Effect of fibronectin fragments on macrophage phagocytosis of gelatinized particles. J. Immunol. 132:1931-1936.
29. Hormann, H., H. Richter, and V. Jelinic. 1985. Fibrinmonomer binding to macrophages mediated by fibrin-binding fibronectin fragments. Thromb. Res. 38:183-194.

30. Heiple, J. M., and L. Ossowski. 1986. Human neutrophil plasminogen activator is localized in specific granules and is translocated to the cell surface by exocytosis. J. Exp. Med. 164:826-840.

31. Collen, D. 1976. Identification and some properties of a new fast-reacting plasmin inhibitor in human plasma. Eur. J. Biochem. 69:209-216.

32. Plow, E. F., D. E. Freaney, J. Plescia, and L. A. Miles. 1986. The plasminogen system and cell surfaces: evidence for plasminogen and urokinase receptors on the same cell type. J. Cell Biol. 103:24112420.

33. Harpel, P. C., and M. W. Mosesson. 1973. Degradation of human fibrinogen by plasma alpha-2 macroglobulin-enzyme complexes. J. Clin. Invest. 52:2175-2184.

34. Jilek, F., and H. Hormann. 1977. Cold-insoluble globulin. II. Plasminolysis of cold-insoluble globulin. Hoppe-Seyler's Z. Physiol. Chem. 358:133-136.

35. Doolittle, R. F., K. W. K. Watt, B. A. Cottrell, D. D. Strong, and $M$. Riley. 1979. The amino acid sequence of the alpha-chain of human fibrinogen. Nature (Lond.). 280:464-468.

36. Pierschbacher, M. D., and E. Ruoslahti. 1984. Cell attachment activity of fibronectin can be duplicated by small synthetic fragments of the molecule. Nature (Lond.). 309:30-33.

37. Ginsberg, M., M. D. Pierschbacher, E. Ruoslahti, G. Marguerie, and E. Plow. 1985. Inhibition of fibronectin binding to platelets by proteolytic fragments and synthetic peptides which support fibroblast adhesion. J. Biol. Chem. 260:3931-3936.

38. Hawiger, J., S. Timmons, M. Kloczewiak, D. D. Strong, and R. F. Doolittle. 1982. Gamma and alpha chains of human fibrinogen possess sites reactive with human platelet receptors. Proc. Natl. Acad. Sci. USA. 79:2068-2071.

39. Ruggeri, Z. M., R. Bader, and L. DeMarco. 1982. Glanzmann's thrombasthenia: deficient binding of von Willebrand factor to thrombin stimulated platelets. Proc. Natl. Acad. Sci. USA. 79:6038-6041.

40. Proctor, R. A., E. Prendergast, and D. F. Mosher. 1982. Fibronectin mediates attachment of Staphylococcus aureus to human neutrophils. Blood. 59:681-687.

41. Gartner, T. K., and J. S. Bennett. 1985. The tetrapeptide analogue of the cell attachment site of fibronectin inhibits platelet aggregation and fibrinogen binding to activated platelets. J. Biol. Chem. 260:11891-11894.

42. Humphries, M. J., K. Olden, and K. M. Yamada. 1986. A synthetic peptide from fibronectin inhibits experimental metastasis of murine melanoma cells. Science (Wash. DC). 233:467-470.

43. Gardner, J. M., and R. O. Hynes. 1985. Interaction of fibronectin with its receptor for platelets. Cell. 42:439-448.

44. Pytela, R., M. D. Pierschbacher, M. H. Ginsberg, E. F. Plow, and E. Ruoslahti. 1986. Platelet membrane glycoprotein IIb/IIIa: member of a family of Arg-Gly-Asp-specific adhesion receptors. Science (Wash. DC). 231:1559-1562.

45. Shirakami, A., Y. Hirai, S. Kawauchi, T. Shigekiyou, T. Takeichi, S. Saito, and K. Miyoshi. 1986. Plasma fibronectin deficiency in eight members of one family. Lancet. i:473-474.

46. Mosher, D. F., and E. M. Williams. 1978. Fibronectin concentration is decreased in plasma of severely ill patients with disseminated intravascular coagulation. J. Lab. Clin. Med. 91:729-735.

47. Cosio, F. G., and A. P. Bakaletz. 1984. Abnormal plasma fibronectin levels in patients with proteinuria. J. Lab. Clin. Med. 104:867-872.

48. Scott, R. L., P. R. Sohmer, and M. G. MacDonald. 1982. The effect of starvation and repletion on plasma fibronectin in man. JAMA (J. Am. Med. Assoc.). 248:2025-2027.

49. Matsuda, M., T. Yamanaka, and A. Matsuda. 1982. Distribution of fibronectin in plasma and liver in liver diseases. Clin. Chim. Acta. 118:191-199.

50. Goodnough, L. T., H. Saito, and O. D. Ratnoff. 1982. Fibro- 
nectin levels in congenital thrombocytopenia: Schulman's Syndrome. N. Engl. J. Med. 306:938-939.

51. Rubli, E., S. Bussard, E. Frei, P. Lunsgaard-Hansen, and E. Pappova. 1983. Plasma fibronectin and associated variables in surgical intensive care patients. Ann. Surg. 197:310-317.

52. Keren, G., P. A. Gordon, S. Lee, M. Stewart, and E. T. Gelfand. 1985. Alterations in plasma-, monocyte-, and lymphocyte-associated fibronectin during cardiopulmonary bypass surgery. Am. J. Clin. Pathol. 83:629-633.

53. Bretz, U., and M. Baggiolini. 1974. Biochemical and morphological characterization of azurophil and specific granules of human neutrophil polymorphonuclear leukocytes. J. Cell Biol. 63:251-269.

54. Spitznagel, J. K., F. G. Dalldorf, M. S. Leffell, J. D. Folds, I. R. H. Welsh, M. H. Cooney, and L. E. Martin. 1974. Character of azurophil and specific granules purified from human polymorphonuclear leukocytes. Lab. Invest. 30:774-785.

55. Janoff, A., B. Sloan, G. Weinbaum, V. Damiano, R. A. Sandhaus, J. Elias, and P. Kimbel. 1977. Experimental emphysema induced with a purified human neutrophil elastase: tissue localization of instilled protease. Am. Rev. Respir. Dis. 115:461-478.

56. LeRoy, E. C., A. Ager, and J. L. Gordon. 1984. Effects of neutrophil elastase and other proteases on porcine aortic endothelial prostaglandin $I_{2}$ production, adenine nucleotide release, and responses to vasoactive agents. J. Clin. Invest. 74:1003-1010.
57. Kornecki, E., Y. H. Erlich, M. Gramse, R. Seitz, and R. Egbring. 1985. Exposure of fibrinogen binding sites by granulocyte elastase induces aggregation of human platelets. Blood. 66:308a. (Abstr.)

58. Wicki, A. N., and K. J. Clemetson. 1985. Structure and function of platelet membrane glycoproteins Ib and V: effects of leukocyte elastase and other proteases on platelets response to von Willebrand factor and thrombin. Eur. J. Biochem. 153:1-11.

59. McGuire, W. W., R. G. Spragg, A. B. Cohen, and C. G. Cochrane. 1982. Studies on the pathogenesis of the adult respiratory distress syndrome. J. Clin. Invest. 69:543-553.

60. Brower, M. S., D. A. Walz, K. E. Garry, and J. W. Fenton II. 1987. Human neutrophil elastase alters human alpha-thrombin function. Limited proteolysis near the gamma-cleavage site results in decreased fibrinogen clotting and platelet-stimulatory activity. Blood. 69:813-819.

61. Brower, M. S., R. I. Levin, and K. Garry. 1985. Human neutrophil elastase modulates platelet function by limited proteolysis of membrane glycoproteins. J. Clin. Invest. 75:657-666.

62. McDonald, J. A., and D. G. Kelley. 1980. Degradation of fibronectin by human leukocyte elastase: release of biologically active fragments. J. Biol. Chem. 255:8848-8858.

63. Plow, E. F., M. Gramse, and K. Havemann. 1983. Immunochemical discrimination of leukocyte elastase from plasmin degradation products of fibrinogen. J. Lab. Clin. Med. 102:858-869. 